\title{
The Relationship between Maternal Plasma Leptin Levels and Fetal Growth Restriction
}

\author{
HiroKo MISE*, ShigeO YURA*,**, HirOAKI ITOH*, MERCy A. NUAMAH*, MAKI TAKEMURA*, \\ NORIMASA SAGAWA*** AND SHINGO FUJII* \\ *Department of Gynecology and Obstetrics, Kyoto University Graduate School of Medicine, 54 Shogoin Kawahara-cho, Sakyo-ku, \\ Kyoto 606-8507, Japan \\ **Precursory Research for Embryonic Science and Technology (PRESTO), Japan Science and Technology Agency (JST), Kawaguchi- \\ City, Saitama, Japan \\ ***Department of Obstetrics and Gynecology, Mie University Graduate School of Medicine, Tsu
}

\begin{abstract}
Leptin is a satiety hormone secreted from the adipose tissue and human placenta. We previously demonstrated that severe preeclampsia up-regulated leptin mRNA expression in the placenta and elevated maternal plasma leptin concentrations. Preeclampsia is frequently related to generation of small for gestational age (SGA) infant especially in cases with severe preeclampsia. However, it is still controversial whether the increase in maternal plasma leptin levels is associated with fetal growth restriction without complication of preeclampsia. Therefore, the aim of the present study was to explore the relationship between maternal plasma leptin levels and fetal growth in non-preeclamptic $(n=98)$ and preeclamptic $(n=40)$ women. In non-preeclamptic pregnant women, plasma leptin levels in SGA group $(n=11)$ were significantly higher than those in appropriate for gestational age (AGA) group ( $\mathrm{n}=87, P<0.05)$. In pregnant women with preeclampsia, likewise, plasma leptin levels in SGA group $(n=15)$ were significantly higher than those in AGA group $(\mathrm{n}=25, P<0.05)$. In multiple linear regression analysis, maternal BMI, mean arterial blood pressure and $\triangle \mathrm{SD}$ of neonatal body weight were significant factors for determining maternal plasma leptin levels in all population studied. Maternal $\mathrm{BMI}$ and $\Delta \mathrm{SD}$ of neonatal body weight showed positive correlation with maternal plasma leptin levels when analysis was performed in non-preeclamptic subjects alone. In conclusion, maternal plasma leptin levels reflect, at least partly, deterioration in fetal growth.
\end{abstract}

Key words: Preeclampsia, Leptin, Placenta, Hypertension, SGA, IUGR

(Endocrine Journal 54: 945-951, 2007)

LEPTIN is a peptide hormone that regulates energy homeostasis, reproductive functions, and immune reactions [1-5]. Leptin is mainly produced in the adipose tissue in non-pregnant human subjects [6-8] and its production is augmented by increased adiposity $[6,9]$. Therefore, leptin serves as a metabolic signal reflecting adiposity to the neuroendocrine and reproductive systems. On the other hand, we and others have

Received: December 27, 2006

Accepted: July 6, 2007

Correspondence to: Shigeo YURA, M.D., Ph.D., Department of Gynecology and Obstetrics, Kyoto University Graduate School of Medicine, 54 Shogoin Kawahara-cho, Sakyo-ku, Kyoto 6068507, Japan demonstrated leptin production from human placental trophoblast cells, which increases plasma leptin levels in pregnant women $[10,11]$. We subsequently demonstrated up-regulation of plasma leptin levels during labor [12]. Thus, we focused on leptin as a trophoblastderived hormone in pregnant women [13].

Preeclampsia is one of the most common disorders during pregnancy [14]. We previously demonstrated that maternal plasma leptin levels as well as leptin mRNA expression in the placenta are significantly increased in pregnant women complicated with severe preeclampsia [15]. Pregnant women with severe preeclampsia often manifest a reduction in uteroplacental blood flow, leading to fetal growth restriction [16]. Accordingly, we hypothesized that increased 
leptin production in the placenta of severe preeclampsia is associated with fetal growth restriction. Similar reduction in uteroplacental perfusion is observed in women complicated with small for gestational age (SGA), even without maternal hypertension [14]. Therefore, in the present study, we investigated the relationship between maternal plasma leptin levels and the disturbance of fetal growth both in non-preeclamptic and preeclamptic pregnant women.

Circulating leptin is bound to some leptin binding proteins $[12,17]$, thus it form two different peaks, when eluted in gel filtration analysis, i.e., bound leptin and free leptin. We have demonstrated a rather constant percent free leptin ratio during pregnancy, despite elevated maternal leptin concentrations, indicating that leptin binding capacity is increased in pregnant women [17]. The physiological and pathophysiological implications of increased leptin and its binding proteins during pregnancy have yet to be fully elucidated. Therefore, we also analyzed the molecular forms of circulating leptin in preeclamptic and non-preeclamptic women with SGA neonates.

\section{Materials and Methods}

\section{Human subjects}

The present study included total 138 singleton Japanese pregnant women whose clinical characteristics were compiled from medical records. Preeclampsia was diagnosed according to the practice bulletin of the American College of Obstetricians and Gynecologists [18]. Hypertension was diagnosed when systolic blood pressure was $140 \mathrm{mmHg}$ or higher and/or diastolic blood pressure $90 \mathrm{mmHg}$ or higher. Mean arterial blood pressure was calculated from systolic and diastolic pressures. Proteinuria was defined as urinary excretion of $0.3 \mathrm{~g}$ protein or more in a $24 \mathrm{~h}$ urine specimen. In the present study, Caesarean section was performed in 26 cases because of fetal distress. SGA neonates were defined when their birth weight was less than 10 percentile of the mean at corresponding gestational age [19]. We divided preeclamptic women into two groups, preeclampsia with SGA neonates and preeclampsia with appropriate for gestational age (AGA) neonates. Non-preeclamptic women were also divided into two groups depending on fetal growth, namely, with SGA neonates or with AGA neonates. Delta standard deviation $(\triangle \mathrm{SD})$ of body weight of neonates were calculated from the birth weight depending on standard Japanese birth weights [19]. Women whose neonates were complicated with anomalies or chromosomal abnormalities were excluded. The present study was approved by the ethical committee on human research of Kyoto University Graduate School of Medicine (No. 90) and conducted with informed consent.

\section{Clinical characteristics of enrolled pregnant women}

Clinical characteristics of enrolled pregnant women are summarized in Table 1. As for maternal age and gestational age at blood sampling, differences among groups are noted. Maternal BMI in preeclamptic women with AGA neonates are higher than that in the other 3 groups. Maternal mean arterial blood pressure and $\Delta \mathrm{SD}$ of neonatal body weight were different among groups as expected from classification of groups.

\section{Preparation of plasma samples and assays}

Plasma samples were collected within 3 weeks before parturition as described previously [15]. Briefly, blood was withdrawn at $0700 \mathrm{~h}-0800 \mathrm{~h}$ from the antecubital vein in a lateral recumbent position after an overnight fast, without labor pain. Collected plasma samples were stored at $-20^{\circ} \mathrm{C}$ until use.

Table 1. Clinical characteristics of pregnant women enrolled in the study.

\begin{tabular}{lcccccc}
\hline & $\mathrm{n}$ & Maternal age & $\begin{array}{c}\text { Gestational } \\
\text { age at sampling }\end{array}$ & $\begin{array}{c}\text { Maternal BMI } \\
\text { at sampling }\end{array}$ & $\begin{array}{c}\text { Maternal } \\
\text { mean arterial BP }\end{array}$ & $\begin{array}{c}\text { Neonatal } \\
\Delta S D\end{array}$ \\
\hline Non-Preeclampsia, AGA & 87 & $28.2 \pm 0.5^{\mathrm{a}}$ & $36.3 \pm 0.2^{\mathrm{a}}$ & $24.5 \pm 0.3^{\mathrm{a}}$ & $87.5 \pm 0.9^{\mathrm{a}}$ & $-0.20 \pm 0.09^{\mathrm{a}}$ \\
Non-Preeclampsia, SGA & 11 & $32.1 \pm 1.6^{\mathrm{b}}$ & $37.0 \pm 0.9^{\mathrm{a}}$ & $23.9 \pm 0.7^{\mathrm{a}}$ & $88.1 \pm 3.1^{\mathrm{a}}$ & $-2.31 \pm 0.22^{\mathrm{b}}$ \\
Preeclampsia, AGA & 25 & $30.5 \pm 1.0^{\mathrm{b}}$ & $35.0 \pm 0.8^{\mathrm{a}, \mathrm{b}}$ & $26.4 \pm 0.8^{\mathrm{b}}$ & $126.4 \pm 3.3^{\mathrm{b}}$ & $-0.70 \pm 0.13^{\mathrm{c}}$ \\
Preeclampsia, SGA & 15 & $30.7 \pm 1.2^{\mathrm{a}, \mathrm{b}}$ & $34.5 \pm 1.2^{\mathrm{b}}$ & $23.7 \pm 0.6^{\mathrm{a}}$ & $129.7 \pm 4.8^{\mathrm{b}}$ & $-2.13 \pm 0.13^{\mathrm{b}}$ \\
\hline
\end{tabular}

a, b, c: Group with different symbol is statistically different from each other. 
Human leptin levels were determined by use of the RIA for human leptin, as previously described $[15,20]$.

\section{Gel permeation chromatography (GPC)}

GPC was performed as described previously [20] on a Sephadex G-50 column $(0.7 \times 50 \mathrm{~cm})$ at room temperature using PBS as elution buffer. Flow rate was $3 \mathrm{ml} / \mathrm{h}$, and fraction volume was $1.0 \mathrm{ml}$. Column was calibrated with blue dextran and recombinant human leptin.

\section{Statistical analysis}

Statistical analysis was performed by ANOVA with Fisher's protected least significance difference (PLSD) test, Pearson's correlation analysis, or stepwise multiple linear regression analysis, where applicable, by StatView analyzer vers. 5 (SAS Institute Inc., Cary, $\mathrm{NC}$, USA). All values are expressed as mean \pm SEM. $P$ values less than 0.05 were regarded as statistically significant.

\section{Results}

Maternal plasma leptin concentrations in preeclamptic women with SGA neonates $(89.1 \pm 16.3 \mathrm{ng} / \mathrm{ml}$, $\mathrm{n}=15$ ) were significantly higher than those in any other group including preeclamptic women with AGA neonates $(61.5 \pm 9.2 \mathrm{ng} / \mathrm{ml}, \mathrm{n}=25, P<0.05)$ (Fig. 1). Plasma leptin concentrations in non-preeclamptic women with SGA neonates $(60.1 \pm 12.5 \mathrm{ng} / \mathrm{ml}, \mathrm{n}=11$, $P<0.05)$ are significantly higher than those in nonpreeclamptic women with AGA neonates $(35.1 \pm 3.1$ $\mathrm{ng} / \mathrm{ml}, \mathrm{n}=87, P<0.001$ ) (Fig. 1). In preeclamptic women, 20 women delivered their babies by emergency Caesarean section due to fetal distress. Maternal plasma leptin concentrations from these 20 women $(93.0 \pm 14.0 \mathrm{ng} / \mathrm{ml})$ were significantly higher than those from preeclamptic women without fetal distress $(46.8 \pm 11.2 \mathrm{ng} / \mathrm{ml}, \mathrm{n}=20, P<0.05)$. In a single correlation analysis, maternal plasma leptin concentrations were negatively correlated with $\triangle \mathrm{SD}$ of neonatal body weight in all studied population $(\mathrm{r}=-0.302, P<0.001$, $\mathrm{n}=138$, Fig. 2A) as well as in non-preeclamptic women $(\mathrm{r}=-0.226, P<0.05, \mathrm{n}=98$, Fig. 2B), but not in preeclamptic population alone ( $n=40$, Fig. $2 \mathrm{C})$.

In order to examine the relationship between mater-

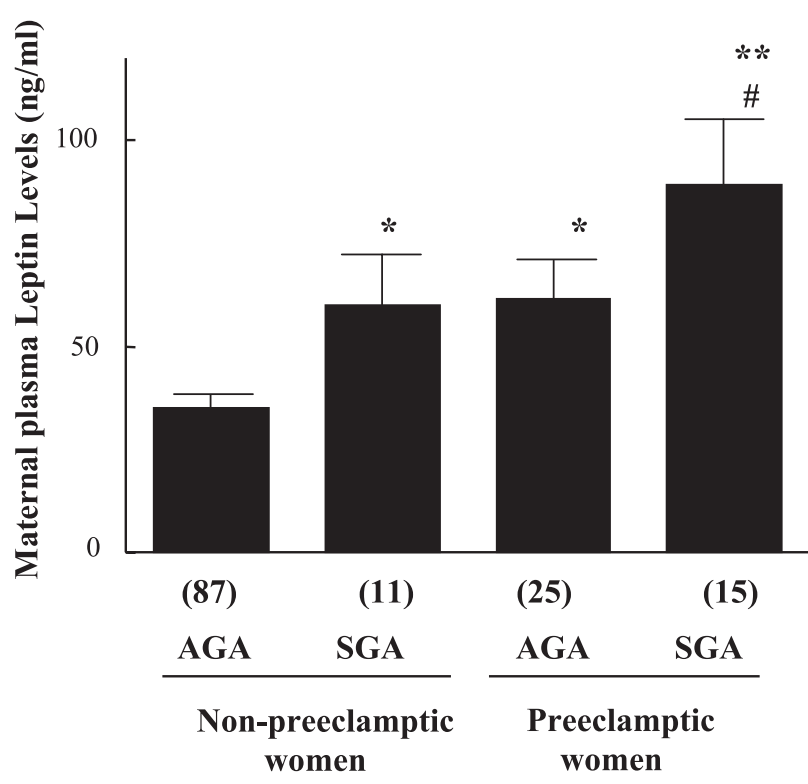

Fig. 1. Maternal plasma leptin levels in non-preeclamptic and preeclamptic women with AGA or SGA neonates. *: $P$ $<0.05$ and $* *: P<0.01$ vs. non-preeclamptic women with AGA neonates, \#: $P<0.05$ vs. preeclamptic women with AGA neonates by ANOVA with Fisher's PLSD.

A)

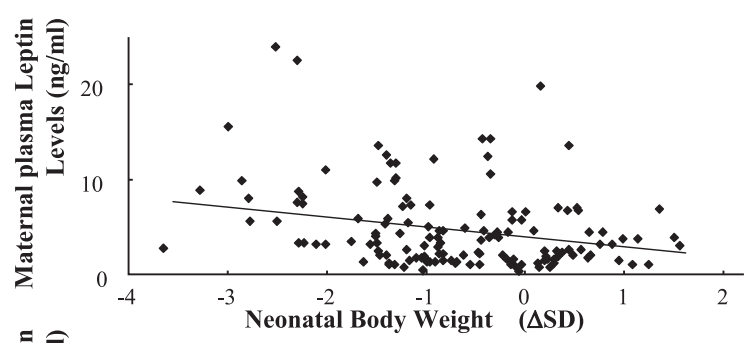

B)

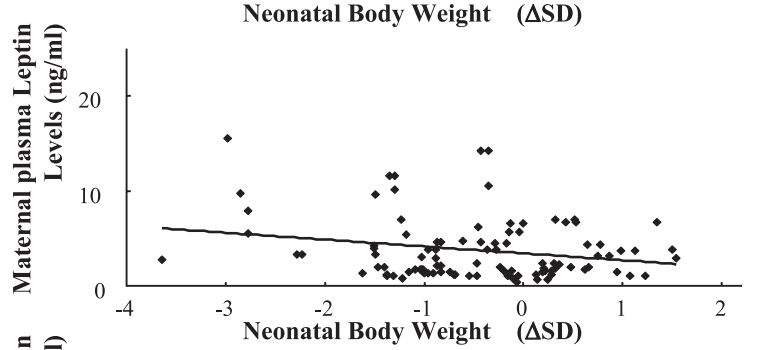

C)

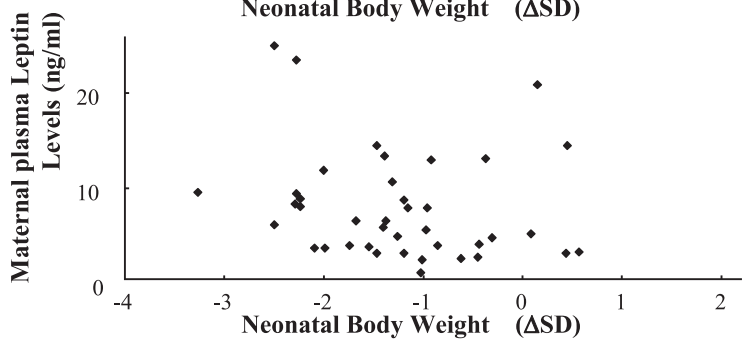

Fig. 2. Scattergram between maternal plasma leptin levels and $\triangle \mathrm{SD}$ of body weight of the neonates in all studied population (A), in non-preeclamptic women (B) and in preeclamptic women $(\mathrm{C})$. 
Table 2. Standardized regression coefficient for maternal plasma leptin concentrations based on a stepwise multiple linear regression analysis

\begin{tabular}{|c|c|c|c|c|c|}
\hline \multirow{2}{*}{ Variable } & \multicolumn{2}{|c|}{ All $n=138$} & \multicolumn{2}{|c|}{ Non-preeclampsia $\mathrm{n}=98$} & \multirow{2}{*}{$\frac{\text { Preeclampsia } n=40}{\text { Coefficient }}$} \\
\hline & Coefficient & $p$ value & Coefficient & $p$ value & \\
\hline Maternal age & n.s. & & n.s. & & n.s. \\
\hline Gestational age at blood sampling & n.s. & & n.s. & & n.s. \\
\hline Maternal BMI at sampling & 0.23 & $<0.01$ & 0.41 & $<0.01$ & n.s. \\
\hline $\begin{array}{l}\text { Maternal mean arterial blood } \\
\text { pressure at sampling }\end{array}$ & 0.29 & $<0.01$ & n.s. & & n.s. \\
\hline$\Delta \mathrm{SD}$ of neonatal body weight & -0.27 & $<0.01$ & -0.32 & $<0.01$ & n.s. \\
\hline
\end{tabular}
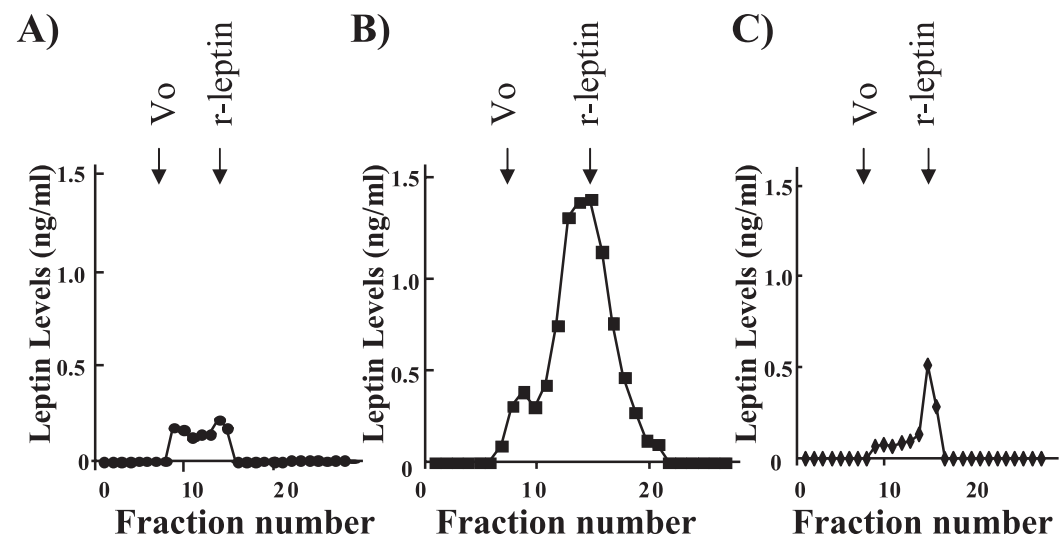

Fig. 3. Representative GPC profile of leptin like immuoreactivity in a normal pregnant woman (plasma leptin concentration: $14.5 \mathrm{ng} /$ $\mathrm{ml}$ (A), preeclamptic woman (plasma leptin concentration: $86.1 \mathrm{ng} / \mathrm{ml}$ ) (B) and non-preeclamptic women with SGA neonate (plasma leptin concentration: $38.6 \mathrm{ng} / \mathrm{ml}$ ) (C). In each panel, two major peaks were observed, a $10 \mathrm{kD}$ of free leptin fraction (fraction No. 14) and a $200 \mathrm{kD}$ large fraction (fraction No. 9), probably corresponding to leptin with binding proteins. Vo; Void volume, r-leptin; elution position of recombinant leptin.

nal plasma leptin concentrations and clinical characteristics of pregnant women, we performed a stepwise multiple linear regression analysis. Maternal age, gestational age at blood sampling, maternal BMI at sampling, mean arterial blood pressure at sampling and $\Delta \mathrm{SD}$ of neonatal body weight were introduced to the analysis. As demonstrated in Table 2, maternal BMI, mean arterial blood pressure and $\Delta \mathrm{SD}$ of neonatal body weight were significant factors for determining maternal plasma leptin concentrations in all studied population. Among them, highest correlation was observed with maternal mean arterial blood pressure at sampling. In order to exclude the effect of maternal hypertensive disorders, we also performed a stepwise multiple linear regression analysis in women without preeclampsia. In this analysis, maternal BMI and $\Delta \mathrm{SD}$ of neonatal body weight were determined to be significant factors for maternal plasma leptin concentrations
(Table 2). Although maternal BMI showed the highest correlation in these populations, $\triangle \mathrm{SD}$ of neonatal body weight also had a significant contribution to maternal plasma leptin concentrations. Maternal ages and gestational ages at blood sampling did not contribute to plasma leptin levels in the analysis of all patients or in the analysis of non-preeclamptic women. In preeclamptic women alone, no variables showed significant correlation with maternal plasma leptin levels.

GPC analysis showed that leptin like immunoreactivity in the plasma of pregnant women with AGA neonates had two peaks, a $10 \mathrm{kD}$ free leptin fraction and an approximately $200 \mathrm{kD}$ large fraction, probably leptin with binding proteins, as was reported in nonpregnant humans [21] (Fig. 3A). In preeclamptic women with SGA neonates as well as in non-preeclamptic women with SGA neonates, plasma leptin like immunoreactivity also showed two similar molecular forms with a 
higher peak of free leptin as compared to that of pregnant women with AGA neonates (Fig. 3B, C).

\section{Discussion}

We have demonstrated that leptin is a novel placenta-derived hormone in humans $[11,13]$. We have also demonstrated that trophoblastic production of leptin is augmented in preeclamptic women [15]. In preeclamptic women, uteroplacental hypoperfusion is frequently observed, leading to growth restriction of the fetus [14]. Placental dysfunction is also suggested in non-preeclamptic women with SGA infants $[22,23]$. However, it has been controversial whether placental leptin production has any correlation with deterioration in fetal growth. Lepercq et al. reported that maternal plasma leptin levels in normotensive pregnant women with SGA neonates were similar to those with AGA neonates, although the mRNA expression, as well as the content, of leptin was augmented in the placenta from normotensive pregnant women with SGA neonates [24]. A recent report by Laivuori et al. also found no significant relationship between maternal plasma leptin concentration and intrauterine fetal growth [10]. However, the number of enrolled women was rather small in these studies. On the other hand, Lea et al. reported that leptin expression is decreased in placenta from women with SGA neonates [25]. Therefore, we investigated the relationship between maternal plasma leptin levels and severity of fetal growth restriction in a larger number of pregnant women complicated with or without preeclampsia. Plasma leptin levels in women with SGA neonates were significantly higher than those in women with AGA neonates both in preeclamptic and non-preeclamptic subjects (Fig. 1). These findings support the report from Pighetti et al. that normotensive women with SGA neonates have higher plasma leptin levels than those with AGA neonates [26]. Moreover, in the present study, we clearly demonstrated negative correlation between maternal plasma leptin levels and $\Delta \mathrm{SD}$ of body weight of neonates in all studied population as well as in non-preeclamptic subjects (Fig. 2, Table 2). These findings suggested that maternal plasma leptin reflect severity of SGA in association with placental dysfunction in pregnant women.

In the present study, calculated maternal mean arterial blood pressure was another significant factor determining maternal plasma leptin concentrations. We represented the severity of preeclampsia by mean arterial blood pressure, because elevated blood pressure is the most important symptom of preeclampsia $[14,16]$. These findings are compatible with our previous observation that severity of preeclampsia is associated with increased maternal plasma leptin levels, and that leptin mRNA expression in the placenta was increased in women with severe preeclampsia [15]. In addition, the present study showed that plasma leptin concentrations in women with fetal distress were higher than those in women without fetal distress. Placental hypoxia due to decreased blood flow and subsequent trophoblastic damage are common pathologies in preeclampsia, which may cause fetal distress in preeclamptic women $[14,16]$. We have demonstrated that hypoxic condition augmented trophoblastic leptin production [15]. These findings suggested that maternal plasma leptin concentrations reflect acute deterioration of placental function that causes fetal distress. On the other hand, maternal plasma leptin concentrations do not correlate with $\Delta \mathrm{SD}$ of body weight of neonates in preeclamptic population (Fig. 2C). Deterioration of placental function sometimes advances rapidly in preeclamptic women accompanied with elevated maternal systemic blood pressure. In such cases, increased placental leptin production may take place, while fetal growth restriction may not become apparent in a short duration. On the contrary, in women with slowly progressing disease, maternal plasma leptin levels may not increase so highly in spite of more apparent restriction in fetal growth. We therefore speculate that placental hypoperfusion, but not fetal growth restriction itself, is associated with increased maternal plasma leptin levels in preeclampsia group.

Plasma leptin level is well known to be correlated with body adiposity in nonpregnant women. As for pregnant women, maternal BMI remains a significant determinant for plasma leptin concentration, as is the case in this study as demonstrated by multiple linear regression analysis. However, we have noted that the correlation between maternal BMI and plasma leptin concentrations becomes weaker during pregnancy, as compared with that in non-pregnant condition [10]. Therefore, we postulated that placental production of leptin may largely contribute to the circulating leptin concentrations in pregnant women. In order to clarify the relative contribution of placenta derived leptin in increased plasma leptin concentrations in SGA pregnancy, further studies with larger numbers of subjects, 
who have similar body adiposity, may be required in future investigation.

In recent experimental study in vitro, leptin was demonstrated to promote cytotrophoblasts to achieve a more invasive phenotype $[27,28]$. Leptin also exerted a stimulatory effect on cytokine secretion and an inhibitory effect on progesterone secretion from human term placental trophoblast cells $[29,30]$. These findings encourage us to investigate, in a further study, the pathological significance of elevated placental leptin production on trophoblast function in women with placental dysfunction.

Circulating leptin is combined with several leptin binding proteins. At least 2 leptin binding proteins (240 and $176 \mathrm{kD}$ ) have been detected in ligand binding blotting [21]. However, leptin binding protein was yet to be clarified precisely, and its physiological function is not well known. We previously demonstrated that in normal pregnant women, free-to-total leptin ratio in maternal plasma is constant throughout pregnancy [17] and during labor [12]. In the present study, protein binding leptin was eluted in one peak in GPC analysis using Sephadex G-50. The magnitude of free leptin fraction was similar to that of protein binding fraction in normal pregnant women (Fig. 3A), which was compatible with our previous observation [17]. In contrast, the former is dominant in preeclamptic women and non-preeclamptic women with SGA neonates (Fig. 3B, C). Our pilot GPC study showed that leptin is present mostly in free form in culture media from dispersed trophoblast cells as well as BeWo cells, suggesting that leptin is secreted from placenta in free form (Mise $\mathrm{H}$, Sagawa N unpublished findings). GPC analysis of placental extract from preeclamptic women showed free form dominant pattern (Mise H, Sagawa N unpublished findings). These findings also support our hypothesis that elevated placental production of leptin contributes to the increase of maternal plasma leptin levels in preeclamptic women as well as in non-preeclamptic women with fetal growth restriction.

In conclusion, the present study indicates that maternal plasma leptin levels correlate with the degree of fetal growth restriction originating from deterioration of placental function, suggesting a pathophysiological significance of increased leptin in pregnant women.

\section{Acknowledgments}

We would like to thank Dr. T. Inoue in Department of Gynecology and Obstetrics, Kyoto University Graduate School of Medicine, Dr. A. Takahashi and Dr. M. Hasegawa in Kurashiki Central Hospital, Dr. F. Kobayashi in Hyogo Prefectural Amagasaki Hospital, Dr. T. Miyamoto in Otsu Red Cross Hospital, and Dr. M. Iwata and Dr. M. Kinoshita in Osaka Red Cross Hospital for their assistance in plasma and tissue samplings. This work was supported in part by research grants from the Japanese Ministry of Education, Science, and Culture (17591728, 17591730, 17659513, 18390446), The Research grant for Cardiovascular Disease from the Ministry of Health, Labor and Welfare, and grants from the Smoking Research Foundation, Takeda Science Foundation, Takeda Medical Research Foundation, Astellas Foundation for Research on Metabolic Disorders, and Precursory Research for Embryonic Science and Technology (PRESTO) of Japan Science and Technology Agency (JST).

\section{References}

1. Zhang Y, Proenca R, Maffei M, Barone M, Leopold L, Friedman JM (1994) Positional cloning of the mouse obese gene and its human homologue. Nature 372: 425-432.

2. Yura S, Ogawa Y, Sagawa N, Masuzaki H, Itoh H, Ebihara K, Aizawa-Abe M, Fujii S, Nakao K (2000) Accelerated puberty and late-onset hypothalamic hypogonadism in female transgenic skinny mice overexpressing leptin. J Clin Invest 105: 749-755.

3. Tartaglia LA, Dembski M, Weng X, Deng N, Culpepper J, Devos R, Richards GJ, Campfield LA, Clark FT, Deeds J, et al. (1995) Identification and expression cloning of a leptin receptor, OB-R. Cell 83: 1263-
1271.

4. Yura S, Itoh H, Sagawa N, Yamamoto H, Masuzaki H, Nakao K, Kawamura M, Takemura M, Kakui K, Ogawa Y, Fujii S (2005) Role of premature leptin surge in obesity resulting from intrauterine undernutrition. Cell Metab 1: 371-378.

5. Lin KC, Sagawa N, Yura S, Itoh H, Fujii S (2005) Simultaneous increases of leptin and gonadotropinreleasing hormone following exogenous estrogen administration in women with normal menstrual cycle. Endocr J 52: 449-454.

6. Friedman JM, Halaas JL (1998) Leptin and the regulation of body weight in mammals. Nature 395: 763 
770.

7. Farooqi IS, Jebb SA, Langmack G, Lawrence E, Cheetham CH, Prentice AM, Hughes IA, McCamish MA, O'Rahilly S (1999) Effects of recombinant leptin therapy in a child with congenital leptin deficiency. $N$ Engl J Med 341: 879-884.

8. Farooqi IS, Matarese G, Lord GM, Keogh JM, Lawrence E, Agwu C, Sanna V, Jebb SA, Perna F, Fontana S, Lechler RI, DePaoli AM, O'Rahilly S (2002) Beneficial effects of leptin on obesity, T cell hyporesponsiveness, and neuroendocrine/metabolic dysfunction of human congenital leptin deficiency. $J$ Clin Invest 110: 1093-1103.

9. Flier JS (2004) Obesity wars: molecular progress confronts an expanding epidemic. Cell 116: 337-350.

10. Laivuori H, Gallaher MJ, Collura L, Crombleholme WR, Markovic N, Rajakumar A, Hubel CA, Roberts JM, Powers RW (2006) Relationships between maternal plasma leptin, placental leptin mRNA and protein in normal pregnancy, pre-eclampsia and intrauterine growth restriction without pre-eclampsia. Mol Hum Reprod 12: 551-556.

11. Masuzaki H, Ogawa Y, Sagawa N, Hosoda K, Matsumoto T, Mise H, Nishimura H, Yoshimasa Y, Tanaka I, Mori T, Nakao K (1997) Nonadipose tissue production of leptin: leptin as a novel placenta-derived hormone in humans. Nat Med 3: 1029-1033.

12. Nuamah MA, Yura S, Sagawa N, Itoh H, Mise H, Korita D, Kakui K, Takemura M, Ogawa Y, Nakao K, Fujii S (2004) Significant increase in maternal plasma leptin concentration in induced delivery: a possible contribution of pro-inflammatory cytokines to placental leptin secretion. Endocr J 51: 177-187.

13. Sagawa N, Yura S, Itoh H, Mise H, Kakui K, Korita D, Takemura M, Nuamah MA, Ogawa Y, Masuzaki H, Nakao K, Fujii S (2002) Role of leptin in pregnancy a review - Placenta 23 Suppl A: S80-S86.

14. Cunningham FG, Leveno KJ, Bloom SL, Hauth JC, Gilstrap LC, Wenstrom KD (2005) Hypertensive disorders in pregnancy. In: Williams Obstetrics. McGrawHill, New York; pp. 761-808.

15. Mise H, Sagawa N, Matsumoto T, Yura S, Nanno H, Itoh H, Mori T, Masuzaki H, Hosoda K, Ogawa Y, Nakao K (1998) Augmented placental production of leptin in preeclampsia: possible involvement of placental hypoxia. J Clin Endocrinol Metab 83: 3225-3229.

16. Redman CW, Sargent IL (2005) Latest advances in understanding preeclampsia. Science 308: 1592-1594.

17. Nuamah MA, Sagawa N, Yura S, Mise H, Itoh H, Ogawa Y, Nakao K, Fujii S (2003) Free-to-total leptin ratio in maternal plasma is constant throughout human pregnancy. Endocr J 50: 421-428.

18. The American College of Obstetricians and Gynecologists 2002 ACOG Practice Bulletin. Diagnosis and Management of Preeclampsia and Eclampsia.

19. Ogawa Y, Iwamura T, Kuriya N, Nishida H, Takeuchi H, Takada M, Itabashi K, Imura S, Isobe K (1998)
Birth size standards by gestational age for Japanese neonates (in Japanese). Nihon Shinseiji Gakkai zasshi 34: 624-632.

20. Hosoda K, Masuzaki H, Ogawa Y, Miyawaki T, Hiraoka J, Hanaoka I, Yasuno A, Nomura T, Fujisawa Y, Yoshimasa Y, Nishi S, Yamori Y, Nakao K (1996) Development of radioimmunoassay for human leptin. Biochem Biophys Res Commun 221: 234-239.

21. Houseknecht KL, Mantzoros CS, Kuliawat R, Hadro E, Flier JS, Kahn BB (1996) Evidence for leptin binding to proteins in serum of rodents and humans: modulation with obesity. Diabetes 45: 1638-1643.

22. Mayhew TM, Wijesekara J, Baker PN, Ong SS (2004) Morphometric evidence that villous development and fetoplacental angiogenesis are compromised by intrauterine growth restriction but not by pre-eclampsia. Placenta 25: 829-833.

23. Papageorghiou AT, Yu CK, Bindra R, Pandis G, Nicolaides KH (2001) Multicenter screening for preeclampsia and fetal growth restriction by transvaginal uterine artery Doppler at 23 weeks of gestation. Ultrasound Obstet Gynecol 18: 441-449.

24. Lepercq J, Guerre-Millo M, Andre J, Cauzac M, Hauguel-de Mouzon S (2003) Leptin: a potential marker of placental insufficiency. Gynecol Obstet Invest 55: 151-155.

25. Lea RG, Howe D, Hannah LT, Bonneau O, Hunter L, Hoggard N (2000) Placental leptin in normal, diabetic and fetal growth-retarded pregnancies. Mol Hum Reprod 6: 763-769.

26. Pighetti M, Tommaselli GA, D'Elia A, Di Carlo C, Mariano A, Di Carlo A, Nappi C (2003) Maternal serum and umbilical cord blood leptin concentrations with fetal growth restriction. Obstet Gynecol 102: 535543.

27. Castellucci M, De Matteis R, Meisser A, Cancello R, Monsurro V, Islami D, Sarzani R, Marzioni D, Cinti S, Bischof P (2000) Leptin modulates extracellular matrix molecules and metalloproteinases: possible implications for trophoblast invasion. Mol Hum Reprod 6: 951-958.

28. Gonzalez RR, Devoto L, Campana A, Bischof P (2001) Effects of leptin, interleukin-1alpha, interleukin-6, and transforming growth factor-beta on markers of trophoblast invasive phenotype: integrins and metalloproteinases. Endocrine 15: 157-164.

29. Cameo P, Bischof P, Calvo JC (2003) Effect of leptin on progesterone, human chorionic gonadotropin, and interleukin- 6 secretion by human term trophoblast cells in culture. Biol Reprod 68: 472-477.

30. Lappas M, Permezel M, Rice GE (2005) Leptin and adiponectin stimulate the release of proinflammatory cytokines and prostaglandins from human placenta and maternal adipose tissue via nuclear factor-kappaB, peroxisomal proliferator-activated receptor-gamma and extracellularly regulated kinase 1/2. Endocrinology 146: 3334-3342. 